\title{
Improving the Surface Quality Through a Laser Scan and Machining Strategy Combining Powder Bed Fusion and Machining Processes
}

\section{Tatsuaki Furumoto ( $\nabla$ furumoto@se.kanazawa-u.ac.jp ) \\ Kanazawa University}

\section{Satoshi Abe}

Kanazawa University

Mitsugu Yamaguchi

Kanazawa University

\section{Akira Hosokawa}

Kanazawa University

\section{Research Article}

Keywords: Hybrid additive manufacturing, Powder bed fusion, Surface machining, Surface quality, Laser scan strategy, Machining strategy

Posted Date: April 16th, 2021

DOl: https://doi.org/10.21203/rs.3.rs-425675/v1

License: (9) This work is licensed under a Creative Commons Attribution 4.0 International License. Read Full License 


\section{Abstract}

This paper focuses on the unconventional laser powder bed fusion (LPBF) technique in which the LPBF and machining processes were executed alternately to fabricate higher quality parts compared to those obtained using subtractive machining processes. The additional machining process changed the stress distribution inside the built part, resulting in the deformation of the surface morphology in the final part. The phenomenon pertaining to the combined LPBF and machining process based fabrication was investigated, and the influence of the process parameters on the formation of the surplus part and deformation of the machined surface was evaluated. In addition, a laser scan and machining strategy was formulated to improve the surface quality of the built part. The surplus buildup at the edge of the fabricated part occurred owing to the difference in the thermal properties between the solidified part and deposited metal powder. The laser-irradiated position at the first layer buildup and energy density were the principal factors affecting the formation of the surplus part, and the surplus buildup could be reduced using the laser scan strategy, in which the laser-irradiated position was shifted inward. The peripheral face of the built part formed periodical steps, owing to the deformation induced by the change in the thermal distribution inside the built part. These steps could be reduced using the machining strategy combining the rough machining process with a finishing allowance and stepwise finishing process.

\section{Full Text}

This preprint is available for download as a PDF.

\section{Figures}
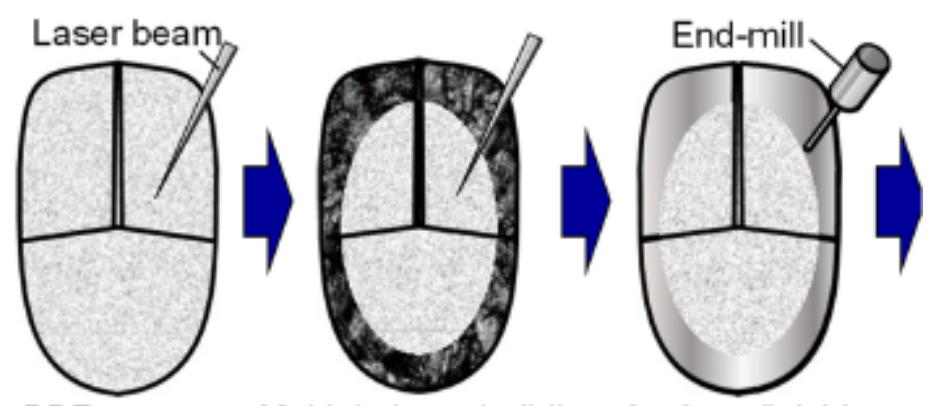

PBF process

Multiple layer building Surface finishing

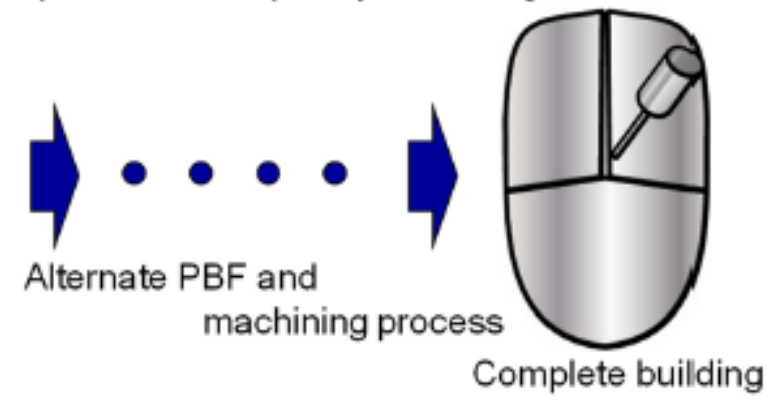

Figure 1 
Buildup process pertaining to hybrid AM equipment combining the LPBF and machining processes
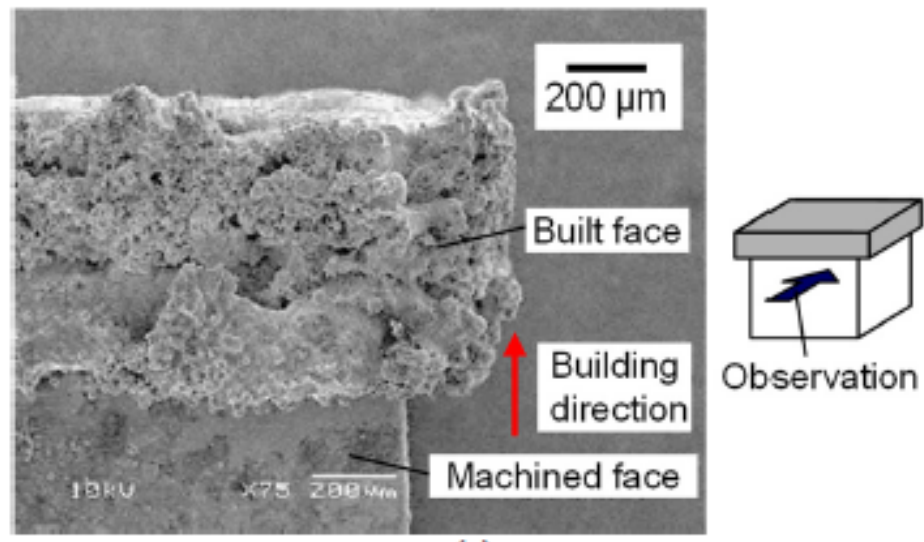

Observation

(a)

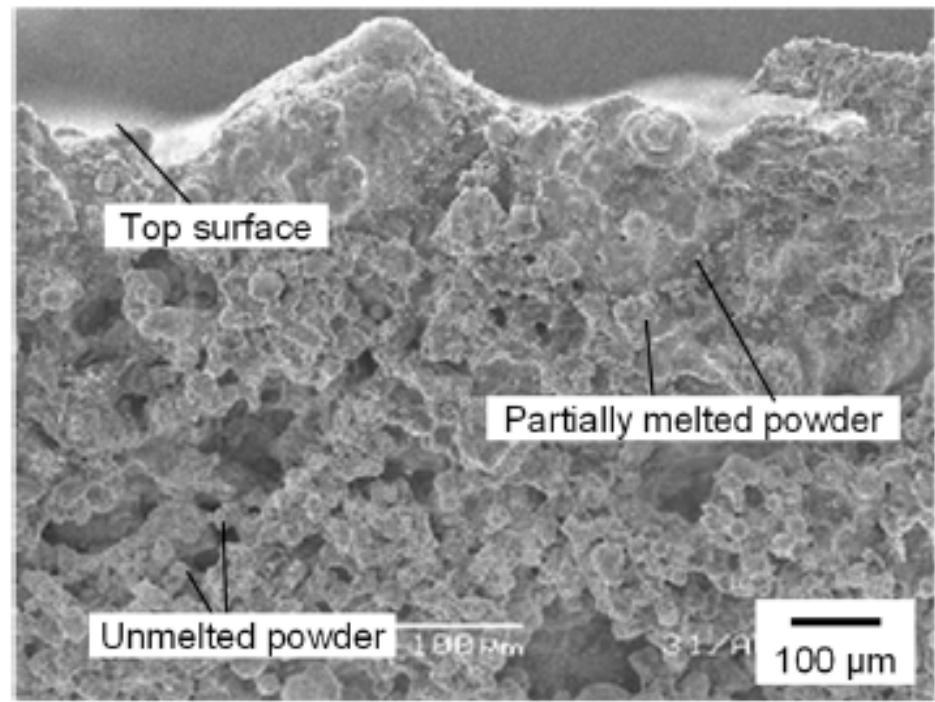

(b)

Figure 2

SEM images of the built part at the boundary of the LPBF processed and machined positions (a) Side view (b) Close up of the LPBF processed surface

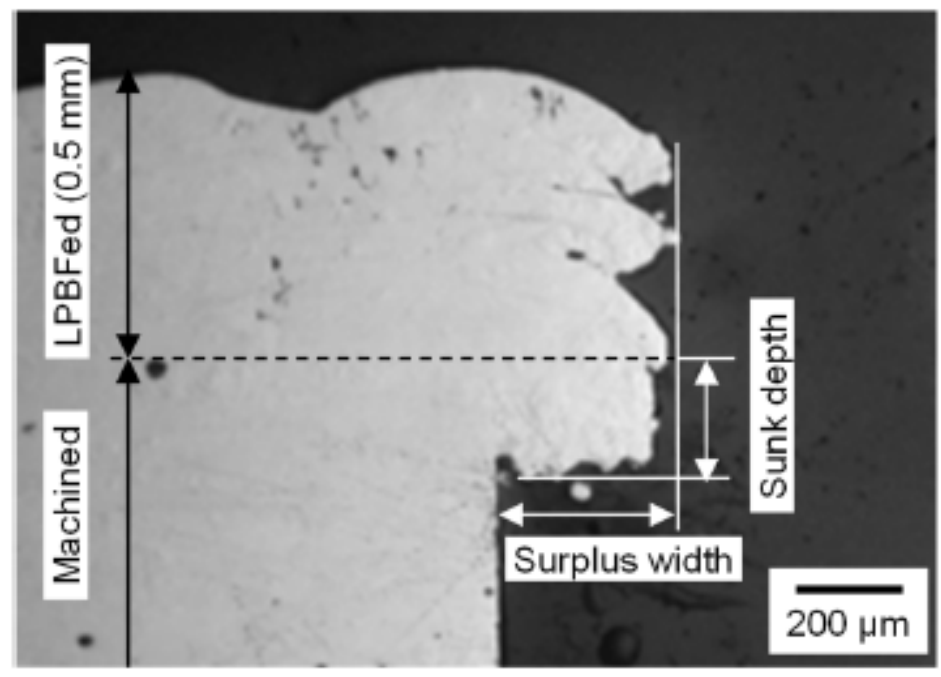




\section{Figure 3}

Cross-sectional image of the built part

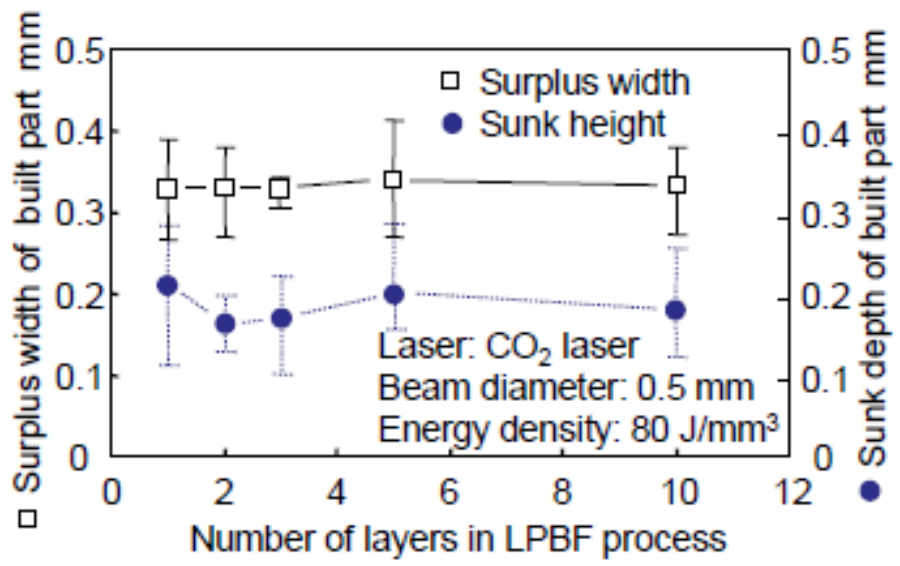

\section{Figure 4}

Variation in the surplus width and sunk depth with the number of layers in the LPBF process

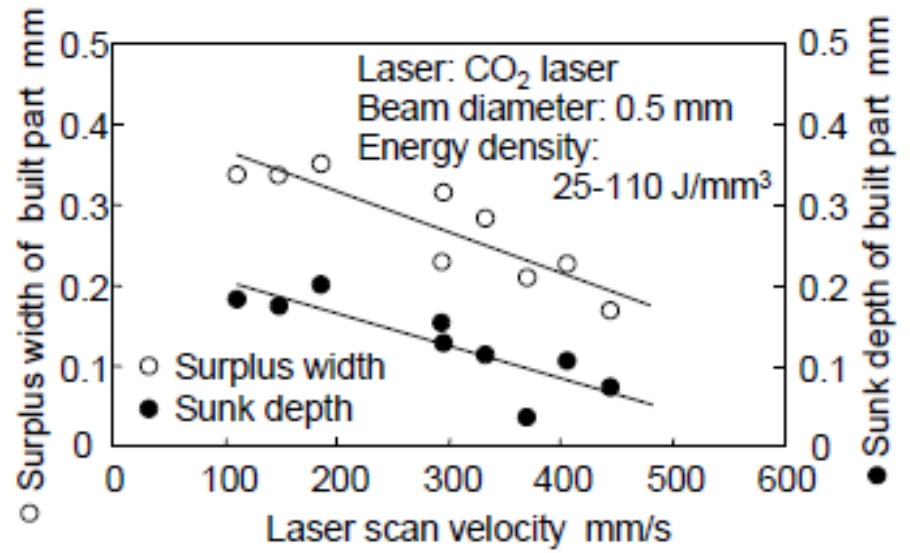

Figure 5

Variation in the surplus width and sunk depth with the laser scan velocity 


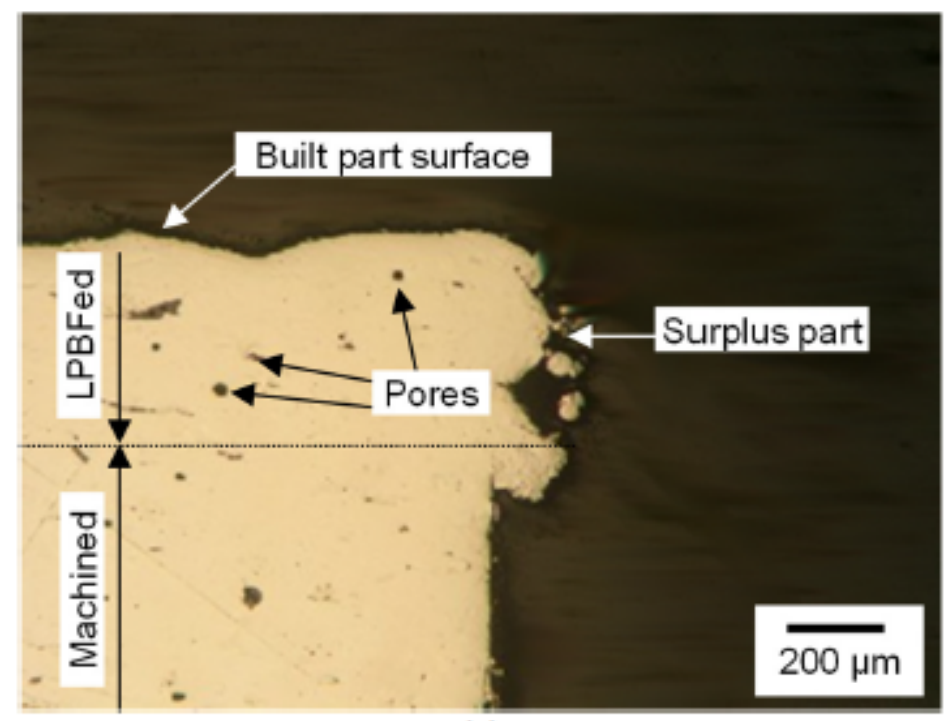

(a)

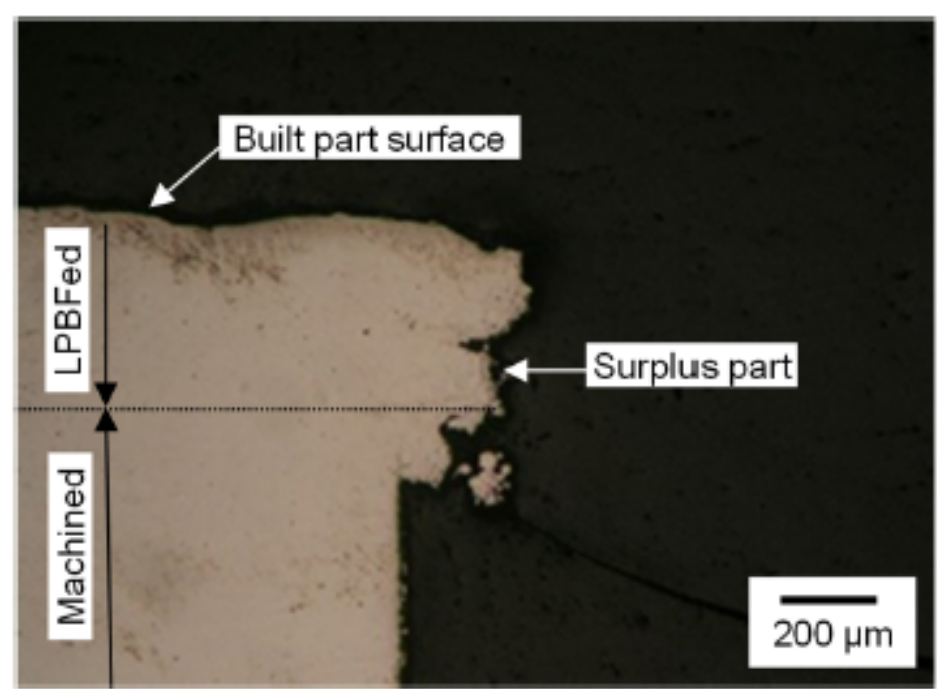

(b)

\section{Figure 6}

Comparison of the cross-sectional images at energy densities of (a) $30 \mathrm{~J} / \mathrm{mm} 3$ and (b) $80 \mathrm{~J} / \mathrm{mm} 3$

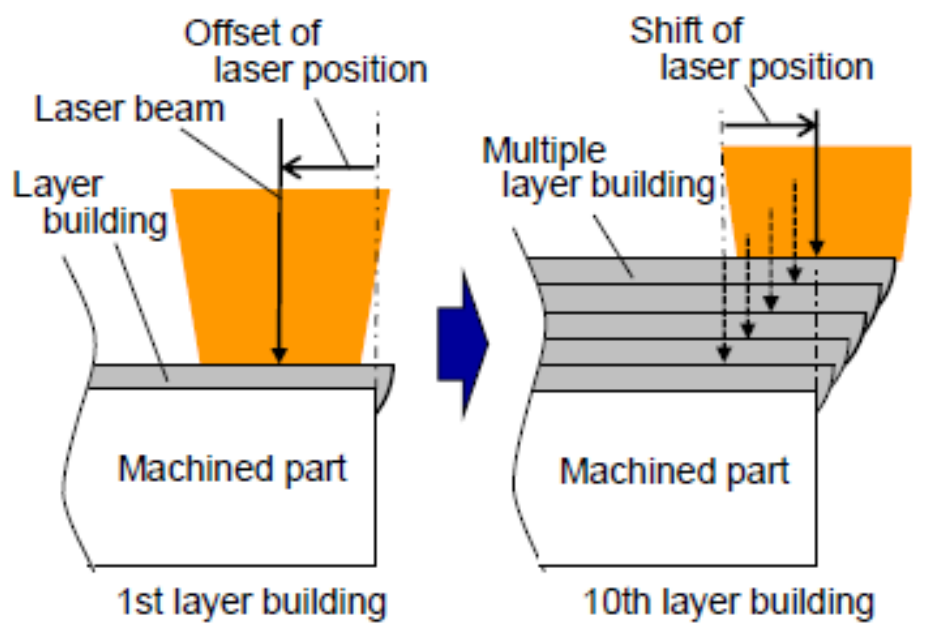


Figure 7

Laser scan strategy to reduce the surplus buildup

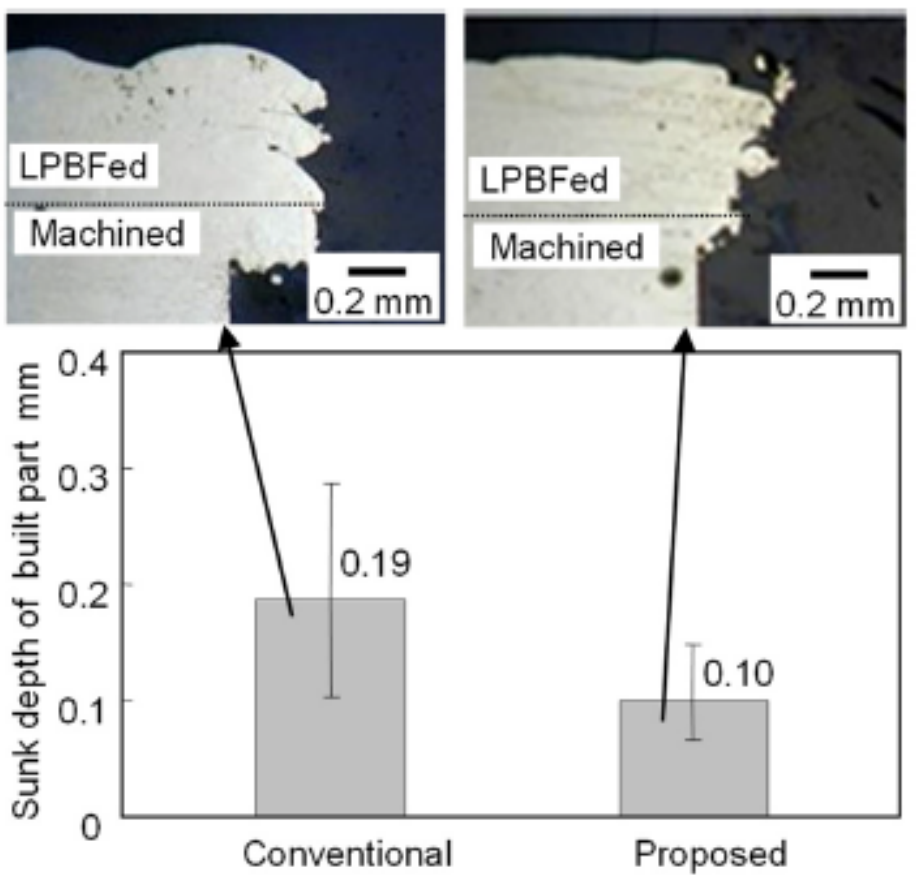

Figure 8

Effect of the laser-irradiated position offset on the surplus buildup

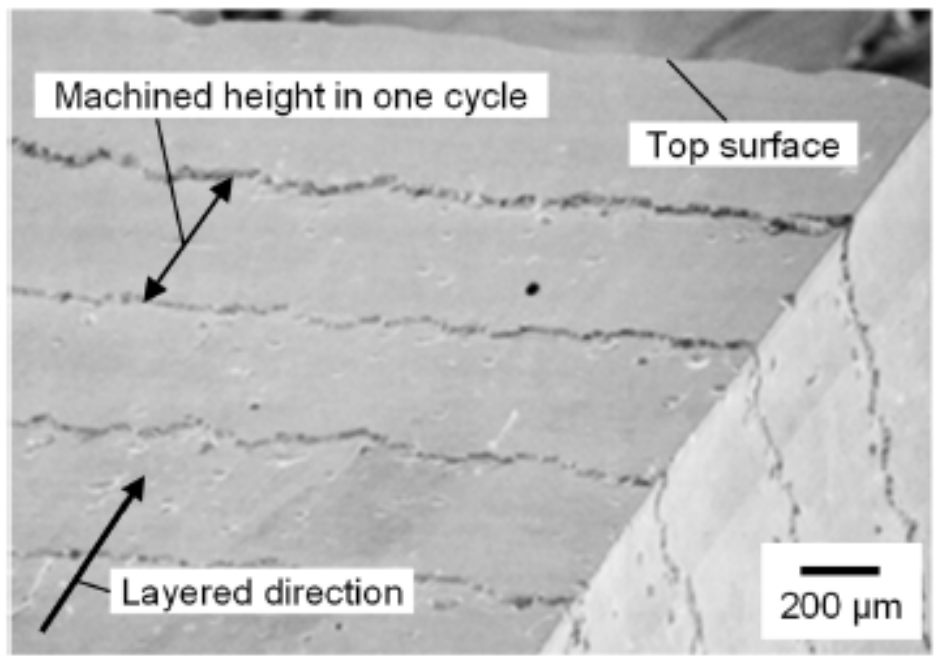

Figure 9

SEM images of the peripheral face after conducting the alternating LPBF and machining processes 


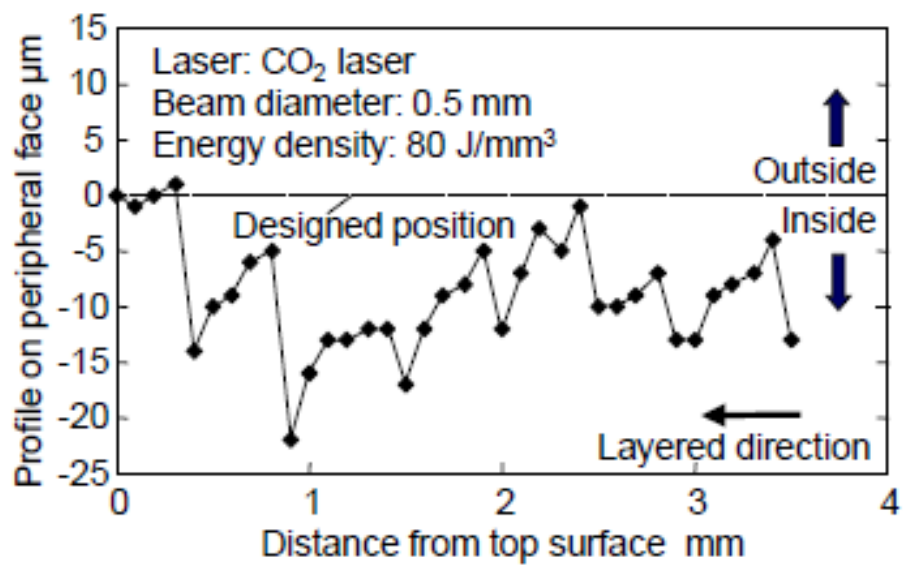

Figure 10

Profile of the peripheral face after conducting the alternating LPBF and machining processes

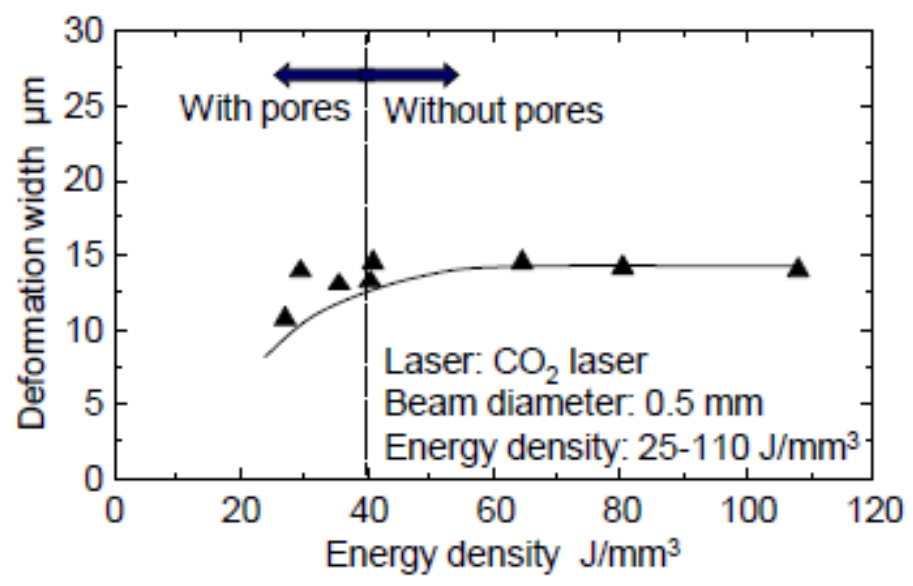

\section{Figure 11}

Variation in the deformation width on the peripheral face with the energy density

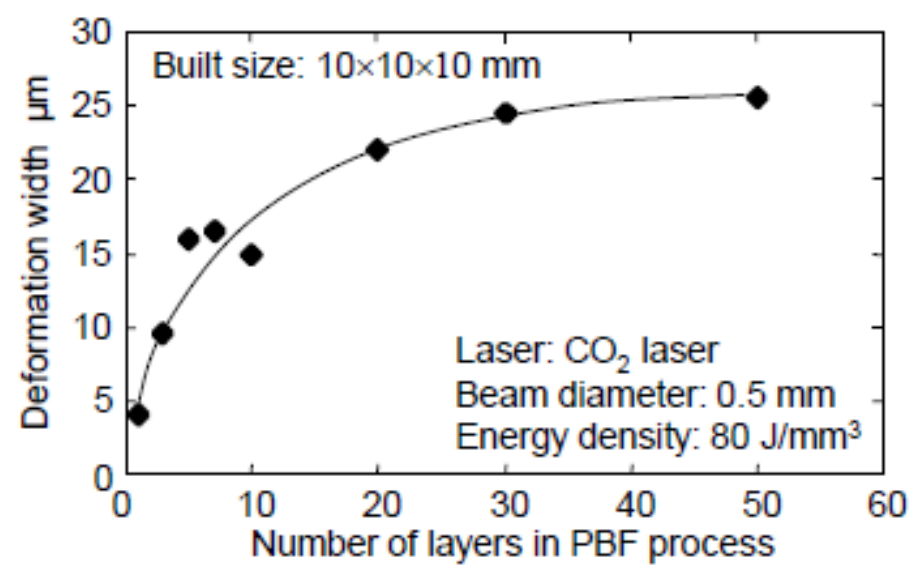

Figure 12

Variation in the deformation width on the peripheral face with the number of layers in the PBF process 


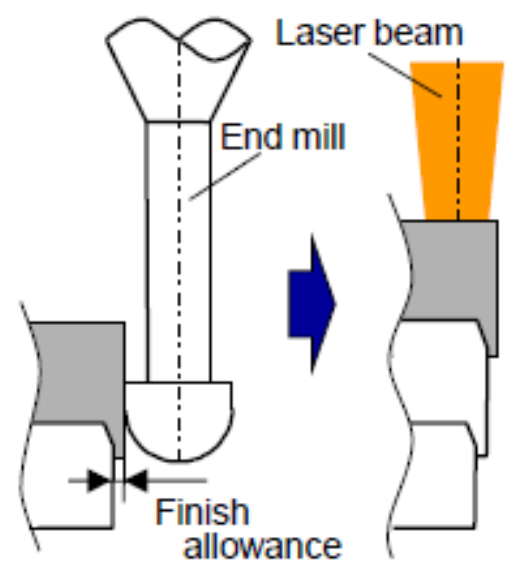

(a) Rough machining (b) LPBF

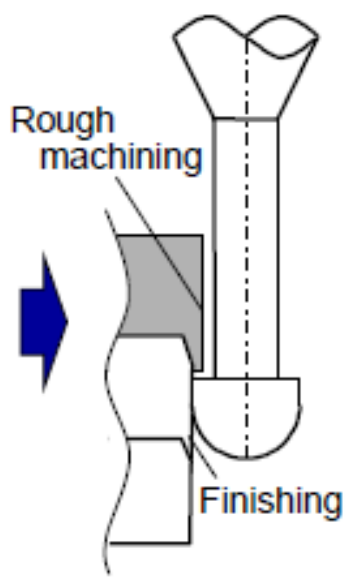

(c) Rough machining and finishing

Figure 13

Proposed approach to improve the peripheral face quality by changing the machining strategy 


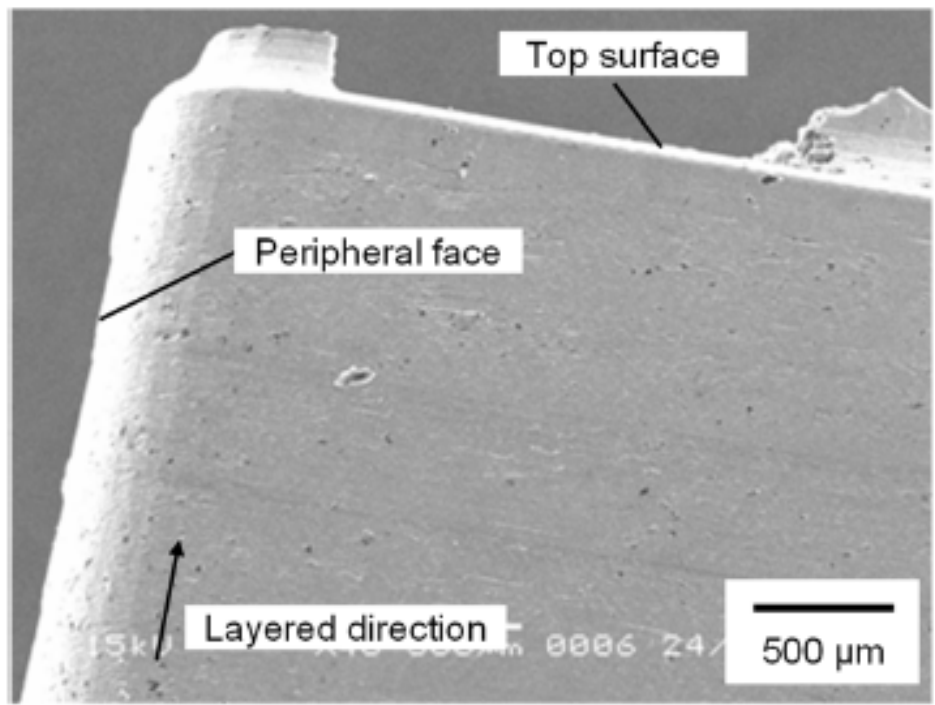

(a)

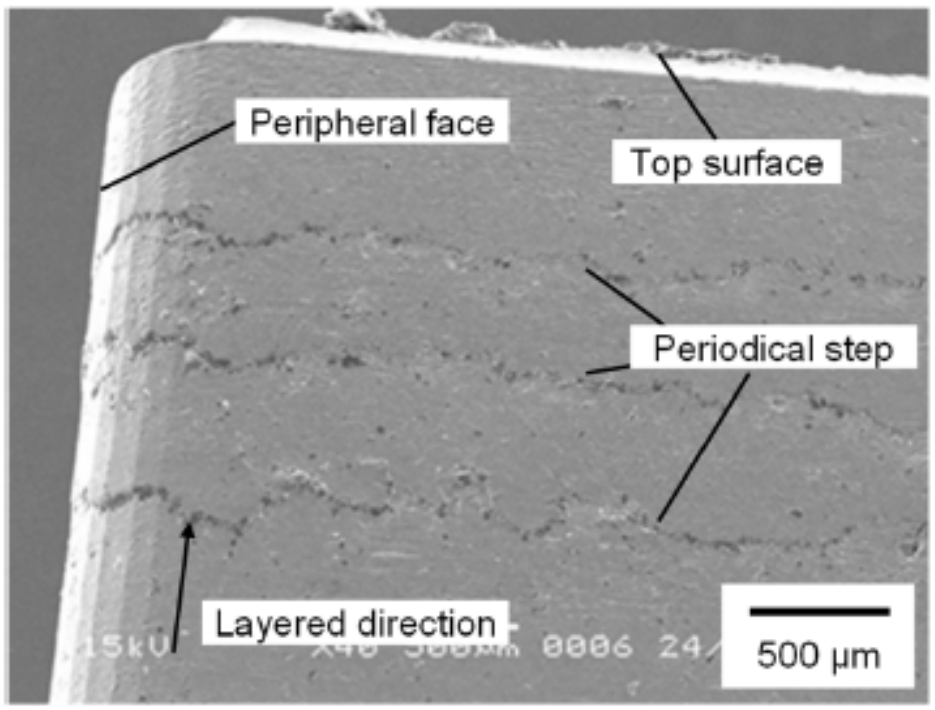

(b)

\section{Figure 14}

Comparison of the SEM images of the peripheral face (a) proposed (b) conventional machining processes 